\title{
Survivin S81A Enhanced TRAIL's Activity in Inducing Apoptosis
}

\author{
Ferry Sandra $^{1,2 *}$, Roya Khosravi-Far ${ }^{1}$ \\ 'Department of Pathology, Harvard Medical School, Beth Israel Deaconess Medical Center, \\ Research North, 99 Brookline Ave., Boston, MA 02215, USA \\ ${ }^{2}$ Section of Oral and Maxillofacial Oncology, Faculty of Dental Science, Kyushu University, \\ 3-1-1- Maidashi, Higashi-ku, Fukuoka 812-8582, Japan \\ *Correspondence: ferrysandra@yahoo.com
}

\section{Abstract}

$\mathrm{B}$ ACKGROUND: Survivin is rarely expressed in normal healthy adult tissues, however, it is upregulated in the majority of cancers. Survivin, which belongs to IAPs family, has been widely reported to protect cells from apoptosis by inhibiting caspases pathway. Survivin's mitotic activity is modulated by many kinases, and its phosphor status can also influence its ability to inhibit apoptosis. There are several important survivin's phosphorylation sites, such as S20 and T34. We have continued our investigation on other potential survivin's phosphorylation sites that could be important site for regulating survivin's cyto-protection.

METHODS: By assuming that $\mathrm{S} 81$ could be a potential target to modify activity of survivin, wild-type survivin (Survivin), antisense survivin (Survivin-AS), mutatedsurvivin Thr34Ala (Survivin-T34A) and mutated-survivin Ser81Ala (Survivin-S81A) were constructed and inserted into pMSCV-IRES-GFP vector with cytomegalovirus (CMV) promoter. Each retroviral product was produced in BOSC23 cells. LY294002 pretreatment and TRAIL treatment along with infection of retroviral products were performed in murine fibrosarcoma L929 cells. For analysis, flow cytometric apoptosis assay and western blot were performed.

RESULTS: In our present study, survivin for providing cytoprotection was regulated by PI3K. The results showed that LY294002, an inhibitor of PI3K, effectively suppressed survivin-modulated cytoprotection in a TRAIL-induced apoptotic model. In addition, mutated survivin S81A showed marked suppression on survivin's cytoprotection. Along with that, TRAIL's apoptotic activity was enhanced for inducing apoptosis.

CONCLUSION: We suggested that survivin could inhibit apoptosis through PI3K and S81A could be another potential target in order to inhibit Survivin-modulated cytoprotection as well as to sensitize efficacy of TRAIL or other related apoptotic inducers.

KEYWORDS: apoptosis, survivin, TRAIL, S81 A, L929, LY294002.

\section{Introduction}

Survivin acts as a suppressor of apoptosis and promotes cell proliferation $(1,2)$. Survivin is rarely expressed in normal healthy adult tissues, however, it is up-regulated in the majority of cancers $(1,2)$. By molecular profiling, survivin has been consistently identified as a risk-associated gene in various malignancies, carrying unfavorable implications for cancer prognosis, disease recurrence and abbreviated survival (1).

Survivin is the smallest member of the Inhibitor of Apoptosis (IAP) gene family, containing 142 amino acid residues (2-4). Unlike other IAPs, survivin contains a single baculovirus IAP repeat (BIR) domain that stretches 
from amino acid residue 15 to $87(2,4)$. Similar to all other IAPs, except X-linked inhibitor of apoptosis (XIAP), survivin does not directly bind caspases (3). The expression of survivin is up-regulated at a transcriptional level by the nuclear factor- $\varkappa \mathrm{B}(\mathrm{NF} \varkappa \mathrm{B})(3,4)$. Survivin can be activated indirectly by growth factors via phosphatidylinositol 3-kinase (PI3K)/Akt pathway (4). On the other hand, survivin is one of the genes repressed at the transcriptional level by wild-type p53 and p75 (4).

Alternative splicing of survivin pre-mRNA from chromosome $17 \mathrm{q} 25$ produces five different mRNAs, which potentially encode five distinct proteins: survivin, survivin $2 B$, survivin $\Delta E x 3$, survivin $3 B$ and survivin $2 \alpha$ (2). It has been proposed that the splice variants function to modulate the function of full-length survivin (4). While this may be true for apoptosis inhibition, where survivin and survivin $\triangle \mathrm{Ex} 3$ interact within the mitochondria to inhibit mitochondrial-dependent apoptosis, recent evidence suggests that the splice variants cannot modulate survivin's function during cell division (4).

When phosphorylated, survivin will gain opposite and balancing effects (1). Phosphorylation of survivin on Thr34 by the mitotic kinase cyclin dependent kinase $1(\mathrm{Cdk} 1)$ has a positive effect, stabilizes survivin at prometaphase and metaphase against proteasomal degradation and heightens an anti-apoptotic threshold in cells traversing mitosis (1). On the other hand, phosphorylation of survivin on Thr117 by Aurora B kinase has a negative effect, lowering its affinity for the interaction with centromeric chromatin (1). Besides these two phosphorylation sides, more other phosphorylation sides of survivin have been reported such as Ser20 (3) and Thr48 (5).

Many studies on regulating survivin have been conducted. For instance, quercetin was reported to promote degradation of survivin in glioma cells (6). Studies on sensitizing TRAIL to induce apoptosis were largely performed in its combination with celecoxib (7), troglitazone (8), celastrol (9), tunicamycin (10), beclin1 (11), capsaicin (12), sodium butyrate (13) and aspirin (14). In addition, there are current approaches to target survivin by anti-sense oligonucleotides, small interfering RNAs, dominant-negative mutants and small molecule antagonists (2).

Ablation of survivin-dependent apoptosis inhibition could improve the efficacy of many agents used to treat cancer (15). In the attempt to target survivin, modulation of its phosphorylation status could be one of the solutions. Since we are interested in knowing survivin's phosphorylation properties, we conducted a study on its potential phosphorylation sites, previously screened by using bioinformatic tools. Here we report our investigation in targeting a phosphorylation site of survivin on Ser81 in order to enhance TRAIL to induce apoptosis.

\section{Methods}

\section{Bioinformatics and Preparation of Survivin Constructs}

An investigation on potential phosphorylation sites was conducted by using Scansite tools (scansite.mit.edu). Sequence of Mus musculus baculoviral IAP repeatcontaining 5 (Birc5)/survivin was in concordance to NCBI reference with gene ID: 11799. Antisense survivin (Survivin-AS) was constructed with 5' HpaI and 3' HpaI sites, while Survivin Thr34Ala (Survivin-T34A) and Ser81 Ala mutants (Survivin-S81A) with 5' BglII and 3' HpaI sites. Each cDNA of Survivin, Survivin-AS, Survivin-T34A and Survivin-S81A were inserted into pMSCV-IRES-GFP vector with cytomegalovirus (CMV) promoter. Each vector was transformed in DH5 $\alpha$ Escherichia coli. Colonies were selected in ampicillin-contained media. cDNA constructs were later purified and confirmed.

\section{Viral Production and Confirmation}

Each cDNA construct $(20 \mu \mathrm{g})$ was transfected in $4 \times 10^{6}$ BOSC23 cells by calcium phosphate method with addition of $10 \mu \mathrm{g}$ of $\mathrm{pCl} 3$-EcotR in $100 \mathrm{~mm}$ plate. Transfection was done for $10 \mathrm{hrs}$ at $37^{\circ} \mathrm{C}$. After transfection, the medium was replaced with fresh DMEM containing 10\% fetal bovine serum (FBS). Cultures were monitored for expression of green fluorescent protein (GFP). Viruses were harvested $72 \mathrm{hrs}$ after transfection. For retroviral tittering, $2 \times 10^{5}$ NIH3T3 cells in $60 \mathrm{~mm}$ plate were infected with $100 \mu \mathrm{l}$ of each virus and addition of $4 \mu \mathrm{g} / \mathrm{ml}$ polybrene for $6 \mathrm{hrs}$ at $37^{\circ} \mathrm{C}$. Then the medium was replaced with fresh DMEM containing $10 \%$ fetal calf serum (FCS). Forty-eight hrs after infection, NIH3T3 cells were collected and measured with a FACSCalibur (Becton Dickinson, Franklin Lakes, NJ, USA). Survivin protein expression of infected cells was determined by immunoblotting, using a rabbit polyclonal to mouse Survivin antibody (Novus Biologicals, Littleton, CO, USA).

\section{Cell Culture and Infection of L929 Cells}

L929 cells were cultured in $\alpha$-MEM containing $10 \%$ horse serum. Infection was carried out using viral product of BOSC23 cells (Survivin, Survivin-AS, Survivin-T34A, Survivin-S81A or vector only) for $48 \mathrm{hrs}$. 


\section{Apoptosis Assay}

Flow cytometric detection of apoptotic cells was performed as described by Sandra et al. (16). Briefly, pretreated cells were harvested and suspended in $1 \mathrm{ml}$ of hypotonic fluorochrome solution $(50 \mu \mathrm{g} / \mathrm{ml}$ propidium iodide in $0.1 \%$ sodium citrate plus $0.1 \%$ Triton X-100). Cell suspensions were placed at $4^{\circ} \mathrm{C}$ in the dark for $2 \mathrm{hrs}$ before the flow cytometric analysis. The propidium iodide fluorescence of individual nuclei was measured with an FACSCalibur (Becton Dickinson).

\section{Immunoblotting}

Treated cells were harvested and incubated with lysis buffer. Samples were separated by SDS-polyacrylamide gel electrophoresis (PAGE) and transferred to a polyvinylidene difluoride (PVDF) sheet. After blocking with 5\% skim milk in Tris-buffered saline (TBS, $150 \mathrm{mM} \mathrm{NaCl}$ and 50 $\mathrm{mM}$ Tris- $\mathrm{HCl}, \mathrm{pH}$ 7.4), the sheets were incubated with first antibody. The second antibody was horseradish peroxidase-conjugated donkey anti-rabbit (Amersham) or sheep anti-mouse (Amersham) IgG antibody, diluted 1:2000. The bound antibodies were visualized using the ECL system (Amersham).

\section{Results}

\section{Survivin expression of L929 cells}

Based on the Scansite tools, S81 was suggested as a potential phosphorylation site of survivin. Therefore, beside T34, S81 mutant was also constructed. Figure 1 shows low basal survivin expression of L929 cells. Marked increase of survivin expression was observed in viral product of Survivin-infected L929 (L929 Survivin) cells. Increased survivin expression was observed in viral product of Survivin-T34A or Survivin-S81A-infected L929 (L929 Survivin-T34A or L929 Survivin-S81A) cells as well. These results implied that viral products of Survivin, Survivin-T34A and Survivin-S81A could perform well. Viral product of Survivin-AS also performed well by eliminating basal survivin expression in viral product of Survivin-AS-infected L929 (L929 Survivin-AS) cells. As a control, viral product of vector did not affect the basal survivin expression in viral product of vector-infected L929 (L929 Vector) cells.

\section{Survivin cytoprotected TRAIL-induced apoptosis in L929 cells through PI3K}

As shown in Figure 2, TRAIL induced apoptosis in L929

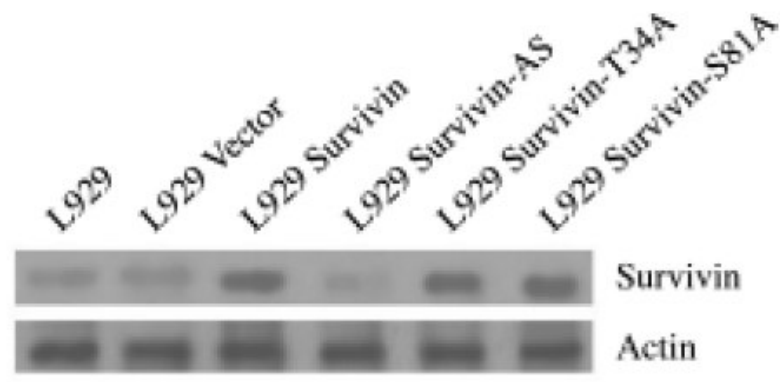

Figure 1. Survivin expression of L929 cells. Each 3×105 L929 cells in $60 \mathrm{~mm}$ plate were/not infected with $75 \times 107$ viral particle/ $\mathrm{ml}$ retrovirus of Survivin, Survivin-AS, Survivin-T34A, Survivin-S81A or vector for $48 \mathrm{hrs}$. Infected cells were cell sorted, then lysed and immunoblotted using rabbit polyclonal to mouse Survivin antibody (Novus Biologicals, Littleton, CO, USA).

cells for $26.70 \%$, and with pretreatment of LY294002, percentage of apoptotic cells was increased to $37.35 \%$. Infection with survivin decreased percentage of TRAILtreated apoptotic cells in viral particle concentration dependent manner. The highest survivin viral concentration, $7.5 \times 10^{7}$ viral particle/ml, cytoprotected TRAIL-induced L929 cells markedly, decrease of apoptotic cells from $26.70 \%$ to $15.04 \%$. However, pretreatment of LY294002 suppressed cytoprotective activity of survivin, a marked increase of the percentage of apoptotic cells was observed in pretreatment of LY294002 on $7.5 \times 10^{7}$ viral particle/ ml-infected L929 cells, marked increase from $15.04 \%$ to $33.03 \%$.

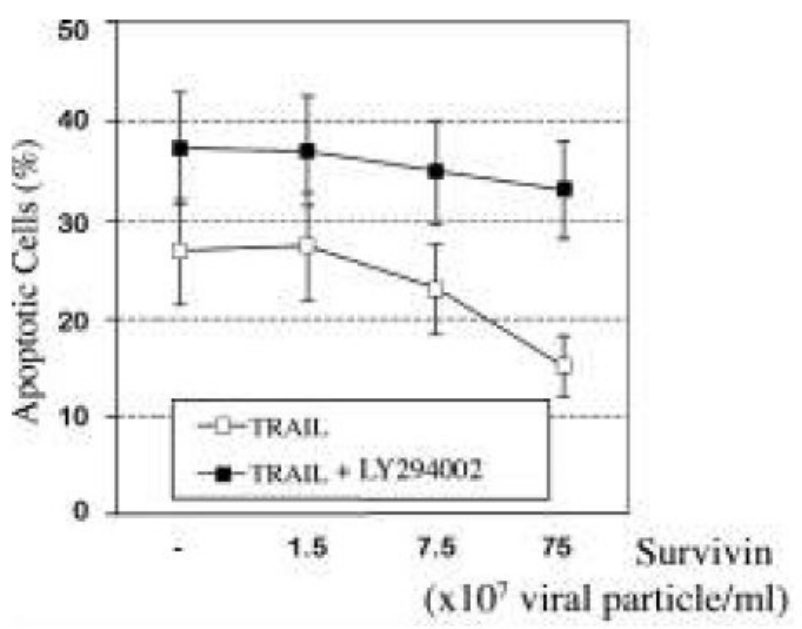

Figure 2. Survivin cytoprotected TRAIL-induced apoptosis in L929 cells through PI3K. Each 3×105 L929 cells in $100 \mathrm{~mm}$ plate were infected with different viral particle concentration of Survivin retrovirus for $48 \mathrm{hrs}$ as indicated in the panel. Pretreatment with/without $25 \mu \mathrm{M}$ LY294002 for $12 \mathrm{hrs}$ was performed prior to treatment of $100 \mathrm{ng} / \mathrm{ml}$ TRAIL for $30 \mathrm{hrs}$. All treated cells were collected and subjected to apoptosis assay. Detailed procedures were described in "Material and Methods". These experiments were repeated 3 times. 


\section{Ser81 site of survivin is important in providing cytoprotection}

As shown in Figure 3, TRAIL induced marked percentage of apoptotic L929 Survivin-AS cells. A result showed that survivin-moderated cytoprotection of L929 Survivin-AS cells was markedly suppressed. Suppressed-cytoprotection of L929 Survivin-T34A and Survivin-S81A cells were also exhibited. Addition of LY294002 did not accelerate percentage of apoptotic L929 Survivin-AS, L929 SurvivinT34A and Survivin-S81A cells.

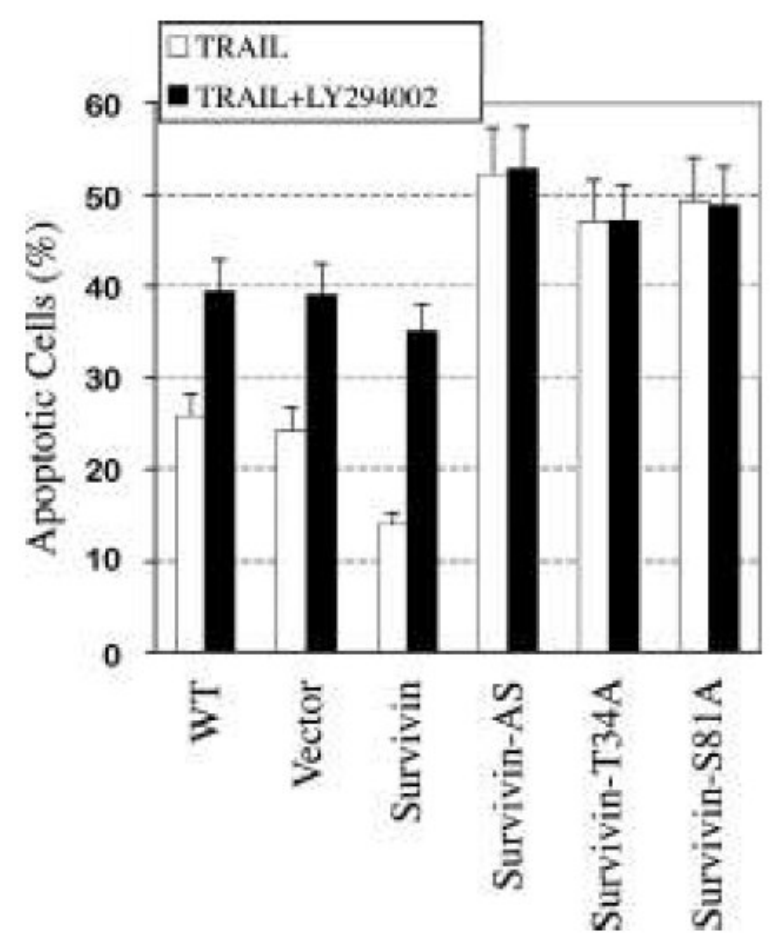

Figure 3. Ser81 site of survivin is important in providing cytoprotection. Each $3 \times 105$ L929 cells in $60 \mathrm{~mm}$ plate were infected with $75 \times 107$ viral particle/ml retrovirus of Survivin, Survivin-AS, Survivin-T34A, Survivin-S81A or vector for $48 \mathrm{hrs}$ and cell sorted. Each $7 \times 105$ sorted L929 cell were re-plated and pretreated with/ without $25 \mu \mathrm{MLY} 294002$ for $12 \mathrm{hrs}$ was performed prior to treatment of $100 \mathrm{ng} / \mathrm{ml}$ TRAIL for $30 \mathrm{hrs}$. All treated cells were collected and subjected to apoptosis assay. Detailed procedures were described in "Material and Methods". These experiments were repeated 3 times. WT: wild type.

\section{Discussions}

Survivin's cytoprotective activity has been reported widely (1-4). Survivin can bind to XIAP. Functionally, a survivin-XIAP complex enhances XIAP stability against ubiquitin-dependent degradation, synergistically increases the activity of XIAP for caspase inhibition, promotes tumor growth in vivo and directly participates in XIAP-mediated intracellular signaling, in particular NF- $x \mathrm{~B}$ activation (3). Survivin blocks apoptosis by mechanisms other than direct effector caspase inhibition $(2,17,18)$. Thus, survivin is now thought to antagonize cell death upstream of effector caspases (2). In one situation, this was accomplished by inhibition of caspase $9(2,19)$. In another, a survivinhepatitis B X-interacting protein (HBXIP) complex bound to pro-caspase- 9 and prevented the recruitment of apoptosis protease activating factor-1 (Apaf-1) to the apoptosome $(2,20)$ A further mechanism by which survivin may inhibit apoptosis is by interacting with second mitochondriaderived activator of caspase (SMAC) / direct IAP-binding protein with low PI (DIABLO), thus displacing bound IAPs $(2,21)$.

Growth factors can activate survivin via PI3K/Akt pathway (4). Additionally, insulin like growth factor $\mathrm{I} / \mathrm{mTOR}$ signaling has been reported to up-regulate survivin $(4,22)$ In our present study, survivin in providing cytoprotection was regulated by PI3K. Results showed that LY294002, an inhibitor of PI3K, effectively suppressed survivin-modulated cytoprotection in a TRAIL-induced apoptotic model. From these results, we assumed that survivin could inhibit apoptosis through PI3K.

Post-translation, survivin's mitotic activity is modulated by many kinases, including $\mathrm{Cdk} 1$, aurora-B and polo-like kinase 1 (plk1) on T34, T117 and S20 respectively $(5,23-27)$ and its phosphostatus can also influence its ability to inhibit cell death (23) Mutation of T34 to a nonphosphorylatable alanine (T34A) abolishes survivin's cytoprotective activity and decreases its stability $(23,28,29)$ Consistent with this, suppression of T34 phosphorylation by cdk1 inhibition also enhances apoptosis $(28,29)$ Based on a bioinformatic study, we found another potential survivin's phosphorylation site, S81. A mutated form of survivin was created to replace potential phosphorylation site on S81 to a nonphosphorylatable alanine (S81A). Our results showed that mutated survivin S81A showed marked suppression on survivin's cytoprotection as well. In addition, TRAIL's apoptotic activity in inducing apoptosis was enhanced. These results suggested that $\mathrm{S} 81$ could be another potential target to inhibit survivin-modulated cytoprotection as well as to sensitize efficacy of TRAIL or other related apoptotic inducers.

\section{Acknowledgement:}

We thank Aristi Papaioannou for laboratory assistance. 


\section{References:}

1. Altieri DC. New wirings in the surviving networks. Oncogene 2008; 27: 6276-84.

2. Ryan BM, O'Donovan N, Duffy MJ. Survivin: A new target for anti-cancer therapy. Cancer Treat Rev 2009; 35: 553-62.

3. Altieri DC. Survivin and IAP protein in cell-death mechanisms. Biochem J 2010; 430: 199-205.

4. Mita AC, Mita MM, Nawrocki ST, Giles FJ. Survivin: Key Regulator of Mitosis and Apoptosis and Novel Target for Cancer Therapeutics. Clin Cancer Res 2008; 14: 5000-5.

5. Barrett RMA, Colnaghi R, Wheatley SP. Threonine 48 in the BIR domain of survivin is critical to its mitotic and anti-apoptotic activities and can be phosphorylated by CK2 in vitro. Cell Cycle 2011; 10: 538-48.

6. Siegelin MD, Reuss DE, Habel A, Rami A, von Deimling A. Quercetin promotes degradation of survivin and thereby enhances death-receptor-mediated apoptosis in glioma cells. Neuro Oncol 2009; 11:122-31.

7. Gaisera T, Becker MR, Habel A, Reussc DE, Ehemanne V, Ramid A, et al. TRAIL-mediated apoptosis in malignant glioma cells is augmented by celecoxib through proteasomal degradation of survivin. Neurosci Lett 2008; 442: 109-13.

8. Schultze K, Böck B, Eckert A, Oevermann L, Ramacher D, Wiestler $\mathrm{O}$, et al. Troglitazone sensitizes tumor cells to TRAIL-induced apoptosis via down-regulation of FLIP and Survivin. Apoptosis 2006; 11: 1503-12.

9. Sung B, Park B, Yadav VR, Aggarwal BB. Celastrol, a Triterpene, Enhances TRAIL-induced Apoptosis through the Downregulation of Cell Survival Proteins and Up-regulation of Death Receptors. J Biol Chem 2010; 285: 11498-507.

10. Zhang HY, Du ZX, Liu BQ, Gao YY, Meng X, Guan Y, et al. Tunicamycin enhances TRAIL-induced apoptosis by inhibition of cyclin D1 and the subsequent downregulation of survivin. Exp Mol Med 2009; 41: 362-9.

11. Niu TK, Cheng Y, Ren $X$, Yang JM. Interaction of Beclin 1 with survivin regulates sensitivity of human glioma cells to TRAIL-induced apoptosis. FEBS Lett 2010; 584: 3519-24.

12. Kim JY, Kim EH, Kim SU, KwonTK, Choi KS. Capsaicin sensitizes malignant glioma cells to TRAIL-mediated apoptosis via DR5 upregulation and survivin downregulation. Carcinogenesis 2010; 31: 367-75.

13. Kim EH, Kim HS, Kim SU, Noh EJ, Lee JS, Choi KS. Sodium butyrate sensitizes human glioma cells to TRAIL-mediated apoptosis through inhibition of $\mathrm{Cdc} 2$ and the subsequent downregulation of survivin and XIAP. Oncogene 2005; 24: 6877-89.

14. Lu M, Strohecker A, Chen F, Kwan T, Bosman J, Jordan VC, et al. Aspirin Sensitizes Cancer Cells to TRAlL-Induced Apoptosis by Reducing Survivin Levels. Clin Cancer Res 2008; 14: 3168-76.

15. Aspe JR, Wall NR. Survivin-T34A: molecular mechanism and therapeutic potential. Onco Targets Ther 2010; 3: 247-54.
16. Sandra F, Matsuda M, Yoshida H, Hirata M. Inositol hexakisphosphate blocks tumor cell growth by activating apoptotic machinery as well as by inhibiting the Akt/NFKBmediated cell survival pathway. Carcinogenesis 2002; 23: 2031-41.

17. Altieri DC. Survivin, cancer networks and pathway-directed drug discovery. Nat Rev Cancer 2008; 81: 61-70.

18. Eckelman BP, Salvesen GS, Scott FL. Human inhibitor of apoptosis proteins: why XIAP is the black sheep of the family. EMBO Rep 2006; 710: 988-94.

19. Dohi T, Beltrami E, Wall NR, Plescia J, Altieri DC. Mitochondrial survivin inhibits apoptosis and promotes tumorigenesis. J Clin Invest 2004; 1148: 1117-27.

20. Marusawa H, Matsuzawa S, Welsh K, Zou H, Armstrong R, Tamm I, et al. HBXIP functions as a cofactor of survivin in apoptosis suppression. EMBO J 2003; 2211: 2729-40.

21. Verhagen AM, Ekert PG, Pakusch M, Silke J, Connolly LM, Reid $\mathrm{GE}$, et al. Identification of DIABLO, a mammalian protein that promotes apoptosis by binding to and antagonizing IAP proteins. Cell 2000; 1021: 43-53.

22. Vaira V, Lee CW, Goel HL, Bosari S, Languino LR, Altieri DC. Regulation of survivin expression by IGF-1/mTOR signaling. Oncogene 2007; 26: 2678-84.

23. O'Connor DS, Grossman D, Plescia J, Li FZ, Zhang H, Villa A, et al. Regulation of apoptosis at cell division by p34(cdc2) phosphorylation of survivin. Proc Natl Acad Sci 2000; 97 : 13103-7.

24. O'Connor DS, Wall NR, Porter ACG, Altieri DC. A p34cdc2 survival checkpoint in cancer. Cancer Cell 2002; 2: 43-54.

25. Wheatley SP, Henzing AJ, Dodson H, Khaled W, Earnshaw WC. Aurora-B phosphorylation in vitro identifies a residue of survivin that is essential for its localization and binding to INCENP in vivo. J Biol Chem 2004; 279: 5655-60.

26. Wheatley SP, Barrett RMA, Andrews PD, Medema RH, Morley SJ, Swedlow JR, et al. Phosphorylation of aurora-B negatively regulates survivin function during mitosis. Cell Cycle 2007; 6: 1220-30.

27. Colnaghi R, Wheatley SP. Liaisons between survivin and plk1 during cell division and cell death. J Biol Chem 2010; 285: 22592-604.

28. Barrett RMA, Osborne TP, Wheatley SP. Phosphorylation of survivin at threonine 34 inhibits its mitotic function and enhances its cytoprotective activity. Cell Cycle 2009; 8: 278-83.

29. Wall NR, O'Connor DS, Plescia J, Pommier Y, Altieri DC. Suppression of survivin phosphorylation on Thr34 by flavopiridol enhances tumour cell apoptosis. Cancer Res 2003; 63: 230-5. 